\title{
Correction: Myeloproliferative leukemia protein activation directly induces fibrocyte differentiation to cause myelofibrosis
}

\author{
T. Maekawa ${ }^{1} \cdot$ Y. Osawa ${ }^{1} \cdot$ T. Izumi ${ }^{1} \cdot$ S. Nagao ${ }^{1} \cdot$ K. Takano ${ }^{1} \cdot$ Y. Okada ${ }^{1} \cdot$ N. Tachi ${ }^{1} \cdot$ M. Teramoto $^{1} \cdot$ T. Kawamura $^{1}$. \\ T. Horiuchi ${ }^{1} \cdot$ R. Saga ${ }^{1}$ - S. Kato ${ }^{1} \cdot$ T. Yamamura ${ }^{1}$. J. Watanabe ${ }^{1}$ - A. Kobayashi ${ }^{1} \cdot$ S. Kobayashi ${ }^{1} \cdot$ K. Sato $^{1}$. \\ M. Hashimoto ${ }^{2}$ S. Suzu ${ }^{2} \cdot$ F. Kimura ${ }^{1}$
}

Published online: 19 September 2018

(c) Springer Nature Limited 2018

Correction to: Leukemia ; https://doi.org/10.1038/leu.2017. 112; published online 3 April 2017

Owing to the insufficient specificity of the anti-myeloproliferative leukemia protein (MPL) antibody in the original version of this Article, Figure 6 and parts of Figures 2a, 4e, and 5a do not represent the correct information. The corrected version of Figure 6 is in this correction and those of Figures $2 \mathrm{a}, 4 \mathrm{e}$, and $5 \mathrm{a}$ are shown in the supplemental information.

Electronic supplementary material The online version of this article (https://doi.org/10.1038/s41375-018-0237-3) contains supplementary material, which is available to authorized users.

T. Maekawa

dri3011@ndmc.ac.jp

1 Division of Hematology, Department of Internal Medicine, National Defense Medical College, Tokorozawa, Japan

2 Suzu Project Laboratory, Center for AIDS Research, Kumamoto University, Kumamoto, Japan 
a

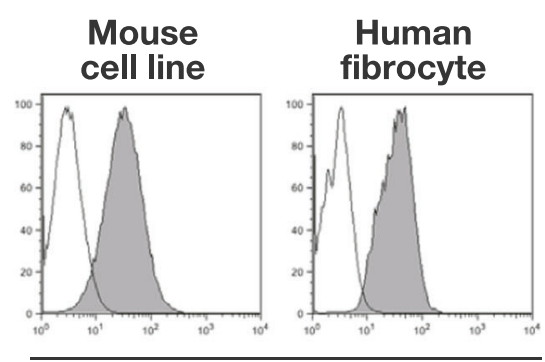

SLAMF7

C

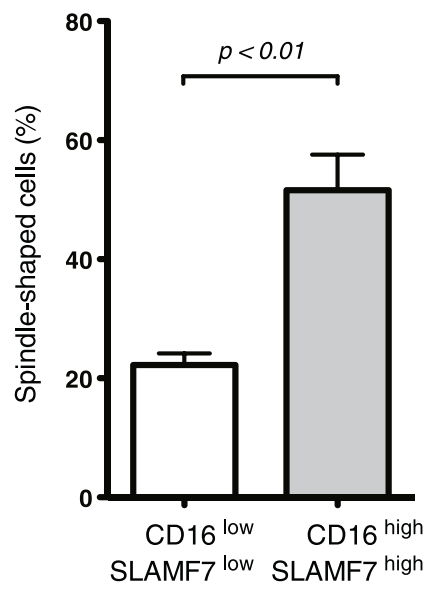

b

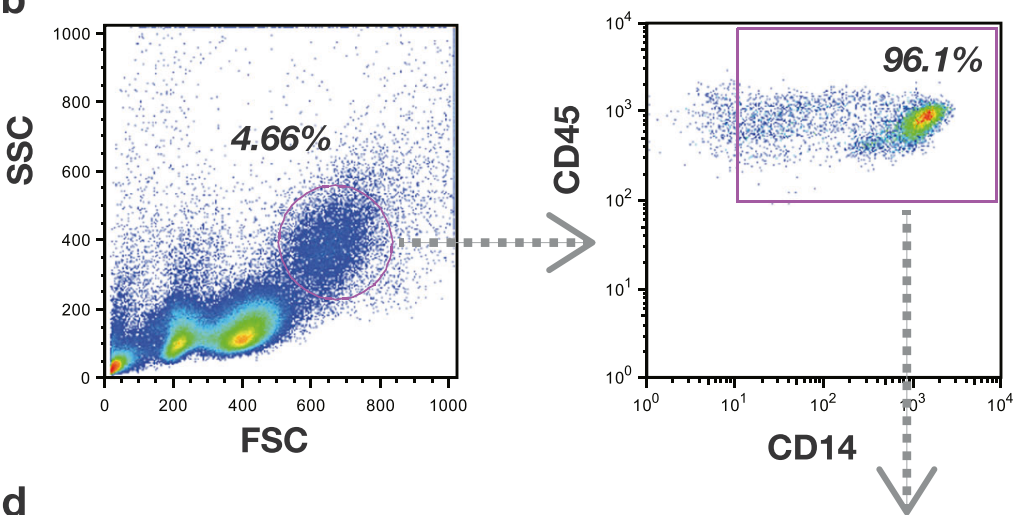

d

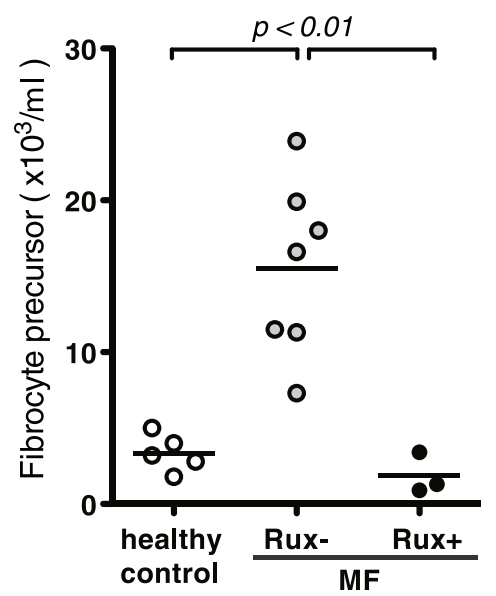

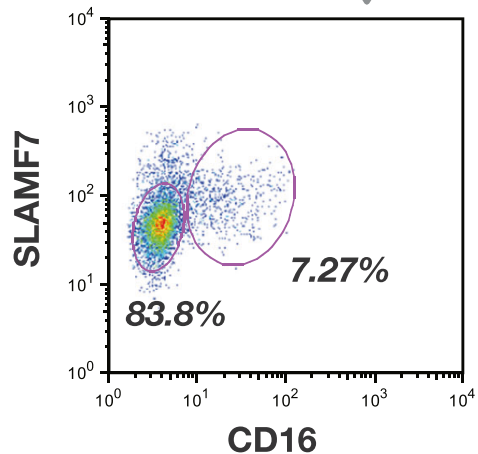

Fig. 6 The number of SLAMF7 $7^{\text {high }} \mathrm{CD} 16^{\text {high }}$ monocytes in human peripheral blood mononuclear cells (PBMCs) were increased in secondary myelofibrosis (MF) patients. a Representative flow cytometry histogram showing the expression of SLAMF7 in the mouse fibrocyte cell line and human cultured fibrocytes. Data are representative of five fibrocyte cell lines and three human cultured fibrocytes. b Approximately $7 \%$ of human $\mathrm{CD}^{+} 5^{+} \mathrm{CD} 14^{+}$monocytes expressed SLAMF $7^{\text {high }}$ CD $16^{\text {high }}$. Data are representative of five human PBMCs from healthy donors. $\mathbf{c}$ The ratio of spindle-shaped cells in human

purified SLAMF7 $7^{\text {high }} \mathrm{CD} 16^{\text {high }}$ monocytes and SLAMF7 ${ }^{\text {low }} \mathrm{CD} 16^{\text {low }}$ monocytes cultured with romiplostim (Rom). A significantly higher frequency of fibrocytes were differentiated from SLAMF7 ${ }^{\text {high }}$ $\mathrm{CD} 16^{\text {high }}$ monocytes (unpaired $t$-test, $P<0.01$ ). d PBMCs of MF patients not treated with ruxolitinib (Rux) contained a significantly higher number of SLAMF7 ${ }^{\text {high }}$ CD16 $6^{\text {high }}$ monocytes than those of healthy donors and MF patients treated with Rux (one-way ANOVA with a Bonferroni correction, $P<0.01)$. The bar indicates the mean 